\title{
Soft, embodied, situated \& connected: enriching interactions with soft wearables
}

\author{
Oscar Tomico $^{1 *}$ and Danielle Wilde ${ }^{2}$
}

\author{
* Correspondence: o.tomico@tue.nl \\ ${ }^{1}$ Eindhoven University of \\ Technology, P.O. Box 513, \\ Eindhoven $5600 \mathrm{MB}$, The \\ Netherlands \\ Full list of author information is \\ available at the end of the article
}

\begin{abstract}
Background: Soft wearables include clothing and textile-based accessories that incorporate smart textiles and soft electronic interfaces to enable responsive and interactive experiences. When designed well, soft wearables leverage the cultural, sociological and material qualities of textiles, fashion and dress; diverse capabilities and meanings of the body; as well as the qualities and capabilities afforded by smart and programmable elements. Textiles behave in particular ways. They are part of culture. No matter a person's views on fashion, dress, their own or others' body, they will have an intimate relationship with textiles, as they are one of the few products worn much of the time, often in direct contact with the body. When designing wearables a designer must consider a range of requirements that do not typically demand focus when designing products that are not worn, including: sensitivity to material detail; an eye for fit and comfort on bodies with diverse shapes and movement capabilities; openness to a diversity of meanings that may be generated; as well as consideration of wearers' intimate relations with technology. Soft wearables allow for greater scope within these requirements.

Results: In this article, we discuss the opportunities and challenges of designing soft wearables, applying notions of situatedness and personal meaning-making to understand and posit values in relation to outcomes. We present three design cases with different uses of the body, material, and context; and reflect on how these different uses impact the design process (challenges and oportunities).

Conclusion: We provide three broad recommendations on how to ideate, explore and prototype to aid wearables research and development to arrive at rich interactions that are soft, embodied, situated and connected.

Keywords: Wearables, Embodied interaction, Crafted interactions, Phenomenology, Soft technologies, H.5.m. Information interfaces and presentation (e.g., $\mathrm{HCl}$ ), Miscellaneous
\end{abstract}

\section{Background}

Using smart textiles and soft electronic interfaces in wearables opens up the opportunity to engage with wearers' senses in diverse and subtle ways. A knitted garment, for example, can deform and reform as the body moves and pushes against the fabric. When augmented with smart capabilities, such deformations may be used to sense engagement and trigger events (Fig. 1). Other fabrics embody still other capabilities, and afford diverse architectures when formed into clothing (Fig. 2). The qualities of interaction made available through these capabilities differ from those that are possible

(C) 2016 The Author(s). Open Access This article is distributed under the terms of the Creative Commons Attribution 4.0 International License (http://creativecommons.org/licenses/by/4.0/), which permits unrestricted use, distribution, and reproduction in any medium, provided you give appropriate credit to the original author(s) and the source, provide a link to the Creative Commons license, and indicate if changes were made. 


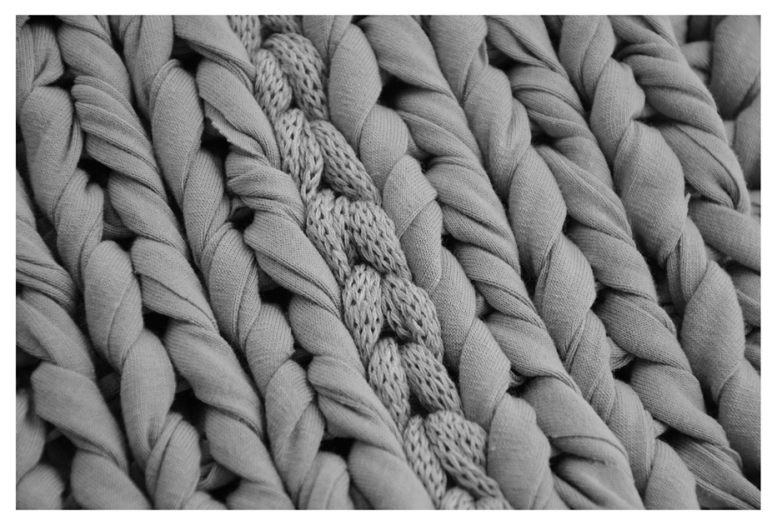

Fig. 1 Knitted textile with an integrated knitted sensor (in the middle)

using gadget-style wearables where components and their surrounding architecture are often rigid (Fig. 3). The inherent flexibility of fabric, potential architecture, and parameters of engagement engender subtle call and response architectures that may not otherwise be enabled. As discussed by Ryan [1], "mobile devices such as phones, music players and tablets fill our lives and reflect a basic need not only for clothing, but for systems of embodiment that can be shared together and support mobility and the embodied dimension of social life." Soft wearables can enable us to move away from screen- and device-centric interactions and regain control of our bodies and surroundings to respond to these needs in ways that are embodied, situated and connected.

Soft wearables draw from divergent disciplines that may be broadly separated into design, production, behaviours and use. Following the industrial revolution, these different and varied aspects-which until then had been handled by master craftsmen and women-moved to the hands of distinct specialists: designers, technicians and social scientists, who undertook their activities in complement. More recently, the proliferation (and resulting democratization) of digital fabrication processes and physical computing platforms have reduced this gap. Nowadays, we can program not only production processes, but materials and their behaviours. However, the opportunities of this (re-) convergence seem constrained by common practices. Technologies that support rapid testing of design, production, behaviour and use enable designing, prototyping and testing to be undertaken in context. Working in context provides many advantages, not least real-world feedback,

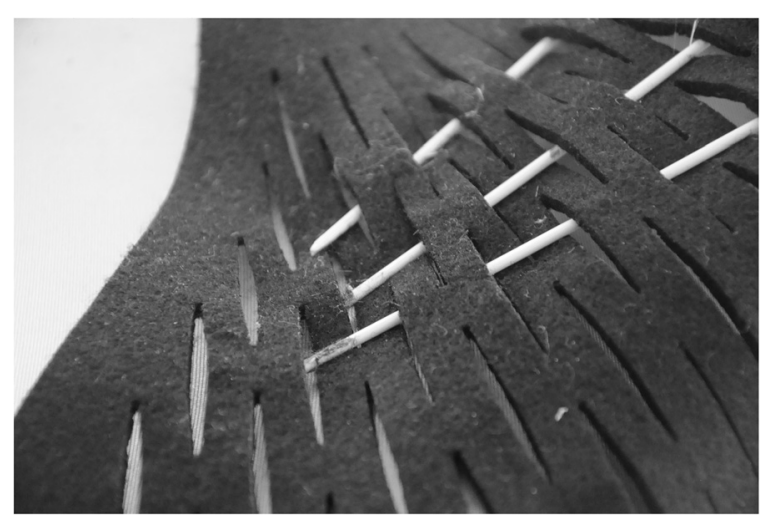

Fig. 2 Laser cut pattern on a synthetic felt allowing for shape-change 


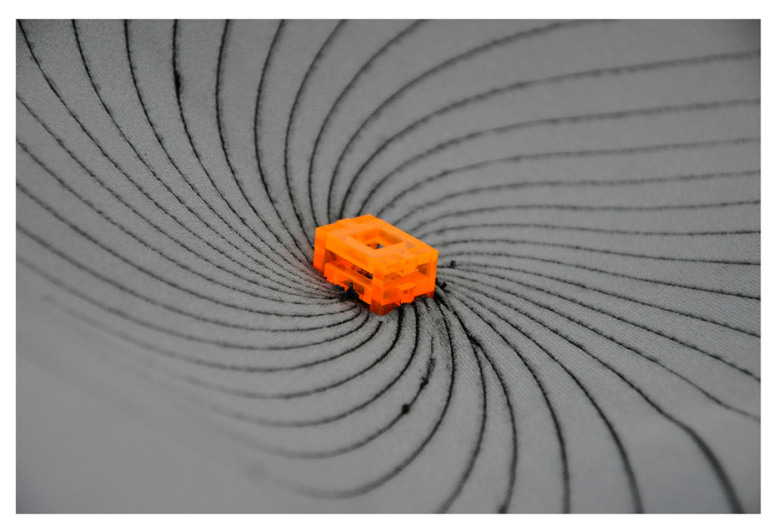

Fig. 3 Integration of vibration motors and 3D printed cases in an laser engraved neoprene textile

during testing, with targeted users. Despite the clear advantage such feedback can give, the trend still seems to be for designers, technicians and other specialists to work at desks, in front of computers, from a distanced perspective-a 3rd point of view. This approach seems to downplay, or at times completely overlook, the fact that bodies are not renderings and behaviour is far more than a thought experiment, no matter how sophisticated the modelling may be. Designing within a representation cannot accurately provide a sense of felt experience, and yet this is how felt experiences are largely designed for and produced.

In this article we argue for the need to redress this imbalance, between representation-as simulated in the lab-and felt experience. We explore the relations between the opportunities and challenges of designing and testing soft wearables in the field, and make explicit the roles of context and the body in material explorations for soft wearables. Following Bryson [2], we consider human garment interactions (HGI) to be a counterpart to Human Computer Interactions (HCI). To do so, we move HCI considerations such as the design of interfaces, the way humans interact with technology, and user experience, into the realm of garments. This approach can play out in a number of ways. In a traditional garment it may mean looking in more depth at the interaction between user and garment in terms of intrinsic bodily behaviours, for example: how the wearer sweats and the wicking properties of the garment. In a soft wearable, how the technology is embodied, the way the user uses their enhanced garment, and how they combine their enhanced garments with other garments and accessories can all affect functionality. These aspects must be considered alongside the HGI considerations that exist before technological capabilities are added to the mix.

To assist designers to think in more nuanced ways about the design of soft wearables-in all of their complexity-we describe in detail the kinds of decisions that we have found to be important to consider. We analyse a series of design projects undertaken in parallel with the same point of departure, facilities and skillsets. These cases demonstrate and articulate a framework for understanding wearables, focused on context and personal meaning-making. Our findings advocate moving the design process from the technologically oriented 'drawing board' to a full immersion in context. Doing so necessarily displaces out-of-the-box thinking for inside-of-the-box thinking. It demands direct engagement with the constraints that come from context, the performing 
body, material properties and functionality, enabling designers to frame 'meaningful' design opportunities.

\section{Methods}

\section{A "soft" design approach to soft wearables: theoretical foundations}

Reclaiming the use of the body and context in the design process requires breaking with historical approaches to wearables development. As discussed in [1], "the engineering philosophy of technology" has been embedded in wearables development since the late 1990s, and continues to this day. This theory builds on Kapp's [3] nineteenth century theories on the origins of technological inventions, which emphasise "analysing the internal structure or nature of technology". As Ryan [1] observes, this perspective is based on "the human drive for prosthetic enhancement", and views technologies as tools categorized according to the part of the body that requires them: "the bent finger becomes a hook, the hollow of the hand a bowl; in the sword, spear, oar, shovel, rake, plow, and spade one observes sundry positions of arm, hand and fingers, the adaptation of which to hunting, fishing, gardening, and field tools is readily apparent" [3] (in [4]). Such thinking is opposed to the tradition of the "humanities philosophy of technology" (personified by [5-7]), which is more concerned with the relationships between technology and other things, and with the meaning of technology. Certainly this is not a clear dichotomy, and some developers move across the two views, though it can be said that a humanities informed approach to wearables development has become much more apparent since the 2000s, as designers have moved into the field [1]. We argue that the humanities approach to wearables is integral to engaging with the full potential of wearables, in particular when they are soft. The "engineering philosophy of technology" requires a cognitive, top down perspective, making it difficult for meaning to emerge from interaction, as interaction is imagined and imposed by the designers rather than treated as an emergent phenomenon. Our starting point on soft wearables runs counter to this idea. It is (specifically and intentionally) a first person perspective based on embodied interaction, strongly connected to the humanities philosophy of technology [8-10].

Philosophical understandings of embodiment are essential to an enriched approach to soft wearables research. With the aim to trigger discussion and provide guidelines for other designers and design researchers, we outline here key considerations when embodied and situated (inter-) actions are the desired outcomes of the development of wearables. As we will demonstrate, Maxine Sheets-Johnson's understanding of movement as not only extra-discursive, but as a precursor to language that underscores cognition ([11]); Andy Clark's research into how extending our capabilities through technologies might enhance thinking ([12]); together with Wilde et al.'s discussion of an entangled approach to movement based design for wearables [13] demonstrate that a wide-ranging understanding of embodiment as situated, cognitive and multidimensional assists the designer to find new opportunities for design.

When well designed, soft wearables should be experienced as an extension or augmentation of the body, rather than as separate from it $[9,12]$. In contrast to the "engineering philosophy of technology", discussed above, the body is not the focus of attention. Rather the body is experienced as the locus: an all encompassing sensing, 
filtering, analysing and reflecting tool. Schön argues that reflective end user designs may be characterized by their situatedness and ability to negotiate various logics and actions [14]. His claims suggest that situating designs in context affords meaning-making for the designer as well as for the end user (whether or not they are involved in development of the design). McCarthy and Wright's research into technology's role in meaning-making through felt experience further strengthens this argument that situated and embodied designs resonate for users [15]. In the case of soft wearables, this way of thinking supports designing for diverse and idiosyncratic movement capabilities, meanings that may be generated, and intimate relations with technology that wearers might bring to the garment. In Entangled... Chris Salter argues that everyone [is] speaking of embodiment, situatedness, presence, and materiality, and everything has become performative [16]. Building on these claims, Wilde [17] argues that, through their inherent performativity, wearables enable the wearer to enact identities. By augmenting the wearer's capabilities, they afford enhanced expression, which empowers the wearer because it emerges from felt experience, rather than being imposed.

Inspirations for this research are found equally in avant-garde artistic movements such as The Situationists (see [18]), who urged artists to place artistic work into everyday settings, where it matters to ordinary people. Situationists tried to create situations that lead people to places and thoughts that they do not visit habitually. As discussed by Gaver et al. in [19], they did this using dérive (roughly, drift) and détournement (roughly, turn-about). Media embedded in ordinary objects, like tablecloths [ibid.], or clothing, may be used to provide such passageways, just as the cases here augment and enrich as they turn-about the experience of their use contexts. Further confirming our findings, Bourriaud [20], in his hugely influential work on relational aesthetics cautioned that what is missing from this notion are other people. Constructed situations might derail people as individuals, but not direct them to see through the social relationships that define their habits. The body is the nexus of experience. The overwhelming seduction of individual sensual experience can be caused to drift, can even be turned-about when designs integrate context, an enriched understanding and engagement with material interactions, enhanced functionality, felt experience, emotions, and social relations, triggered through context.

\section{Results}

Understanding material, body and context relations: the practice of soft wearables design

Foregrounding and cycling through these considerations allows designers to create new kinds of objects situated on an axis between garments and products. Rather than fitting clearly into existing, recognisable domains, such wearables define their own domain, allowing designers to break with the limitations and pre-conceived notions attached to disciplines such as fashion, textile design, $\mathrm{HCI}$ and electronic product design. New functionalities require new forms, interactions and materials, as well as new approaches. It is from the emerging relations between: context, form, function, material and interaction-powered by the moving body-that a rich, experiential soft wearable design may emerge.

Design Researchers engaged with this problematic use different approaches. Some use the body and movement as a material. Wilde, Schiphorst \& Klooster, for example, meld performing arts and interaction design techniques in their research [13]. Höök 
and colleagues at Mobile Life, SICS and KTH use Mindfulness and Somaesthetics [21] to develop theories and practices around core mechanics and experiential artefacts [22]; Kozel and Hansen develop improvisational methods using dance and phenomenology to design for intimacy [23, 24]; Andersen with Schiphorst [25], and Corness, also with Schiphorst [26] use performance-based methods and performer technique to bring focus to the knowing body. Stjernholm [27] looks at relations between the processes of creating, performing, and perceiving aesthetic embodied practices with digital media. Kirsh [28] explores the question of physical thinking, using the body as an instrument of cognition, and Ross [29] uses aesthetic experience as a mechanism for design.

Other researchers focus on developing movement skills. Hummels, Overbeeke and Klooster [30], for example, have long championed the need for the designer as movement expert, foregrounding the expressive power of gesture. Djajadiningrat, Matthews and Stienstra [31] stress the importance of skilled action when designing interaction, bringing focus to the experience of use. Yet others focus on designing representations of movement, evaluating the user experience, mapping interactions, or exploring sensing technologies [32]. Uğur [33], for example, designed garments that can communicate the emotions of the wearer as dynamic tangible interfaces and extensions of the human body; and Jeon [34], has created dynamic tactile experiences that invite people to interact for their own comfort.

Following, we describe, analyze and reflect on material, body and context relations in soft wearable design through three projects developed during the Close to the Body project, a 2013 collaboration between ESDI, ${ }^{1}$ IAAC $^{2}$ and TU/e. ${ }^{3}$ In Close to the Body, four multidisciplinary groups of design students spanning architecture, fashion and interaction design worked together to develop three iterations of designs using identical brief, process, facilities and skills. Ideation, material exploration, and prototyping was different in each case. We highlight three designs: Open Up, Sound Embracers and Trailblazer. To facilitate reflection on how collocated interactions might further enrich situated and performative meaning-making with soft wearables, we focus on the role of material explorations, the body and context in each design process. Using three iterations of each wearable to represent 3 moments in unfolding time, we reflect on the changes that occur in the relations between material, body and context as different foci are foregrounded.

\section{Material explorations}

Open Up (Figs. 4, 5 and 6) is a symbiotic outfit that measures displacement, and through material feedback, gives its wearer a new sense of the environment. The work is inspired by animal behaviours. In particular, the methods animals use to attract each other. The goal of Open Up's first iteration (Fig. 4) was to support relaxation in the mountains (for example through an enhanced experience of yoga). The prototype consisted of a basic natural woollen felt t-shirt-like enclosure that served as a support for a hand-actuated mechanism opening and closing wind catching nets. Moving the arms expanded these wind-catching nets, creating an extended (physical) feeling of the air. Physically connecting the hands and the net additionally made the wearer feel the weight of the wind on their shoulders.

In the second iteration of Open Up (Fig. 5) the context of application shifted from relaxation in the mountains to the everyday activity of walking. Instead of feeling the air, 


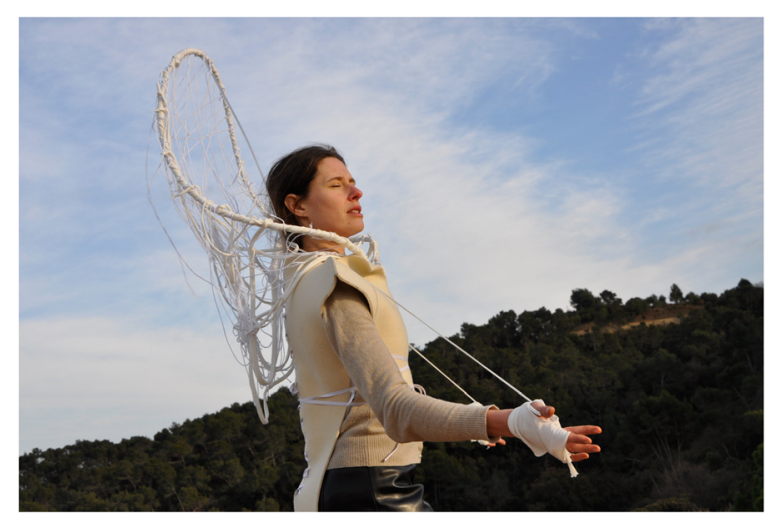

Fig. 4 Open Up (v.1) is made of wind-catching nets. It relates to the body by creating an extended feeling of air. Its context of use is relaxation

the wearer could feel their 'personal' space being transgressed by people around them as they walked. Proximity sensors were used to sense approaching people. When a certain threshold was breached, the garment changed shape. An automated mechanism attached to the supporting structure would move two metal rods up and down, opening and closing the nets. The supporting structure on the body played a similar role in version 1 and 2, thus becoming the 'red thread' of the design. In the final iteration (Fig. 6) Open Up was conceived as a cocktail dress that changes shape when people approach. The aim of this version is to ensure the wearer is being noticed. The supporting structure was made using black synthetic felt, with special cuttings to make it more fashionable. The "surprise" opening-up effects are achieved using the same proximity sensors and moving rods from iteration 2 but in this case the reaction is programed to be faster and more energetic.

The design process for Open Up relied heavily on material explorations of mechanisms that can trigger movement: wind-catching nets, rods, and their attachment to the body through a garment. The principle design action throughout was material explorations, undertaken on a table, then transferred to the body. As each new idea emerged, the context of application and the role of the body shifted. Open Up began as a relaxation aid that allows the wearer to feel at one with the environment. When the context changed to walking in a city, the wearable's use transformed into visualizing

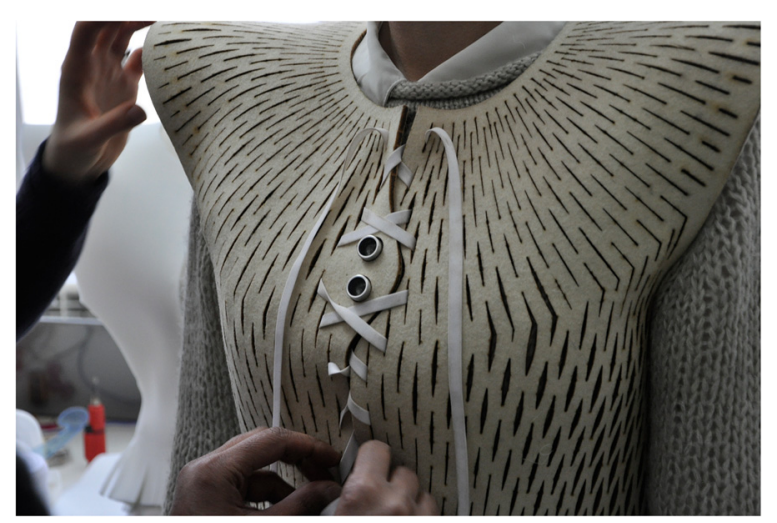

Fig. 5 Open Up (v.2) is made of proximity sensors and laser cut felt. It relates to the body by letting feel if something trespasses your 'personal' space. Its context of use is everyday life (e.g., walking on the streets) 


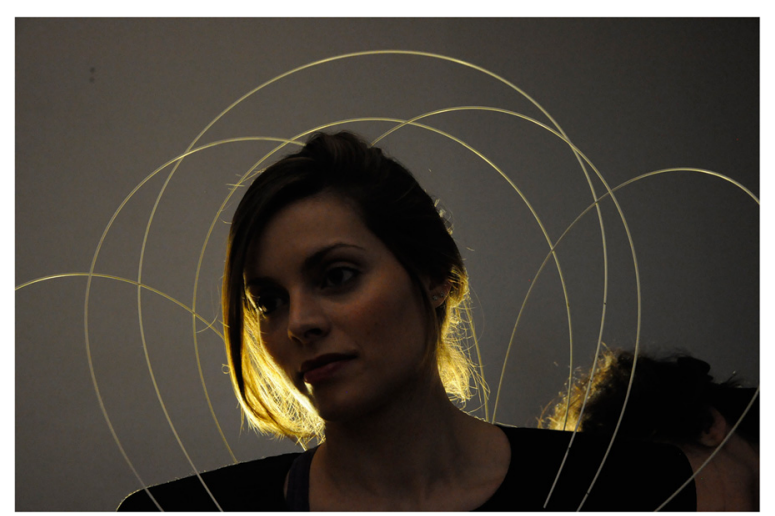

Fig. 6 Open Up (v.3) is made of proximity sensors, motors and moving rods. It relates to the body by changing your siluette rapidly to be noticed. Its context of use is drawing attention in a cocktail party

the distance between the wearer and others. Finally, visualizing distance was used to create a dramatic entrance effect in parties when approaching the crowd.

Framing the design process by means of material explorations allows a designer to continuously try out new ideas, and thus expand the design space, or broad context of use (e.g., relaxation, protection, cocktail dress). However, it doesn't support decisionmaking or depth. There is always a new context, a new application, a new idea that can alter the design. Moreover, the concepts remain in an early stage, a first answer to a challenge (e.g., what if it could...). In this approach, reasoning is driven by how ideas fit with materials at hand, making it imagined but not lived. This process is not uncommon in DIY communities where statements like wouldn't it be cool to... exemplify a continuous search for the 'next cool thing'. Material explorations for the sake of material explorations may thus avoid engaging in deep ways with personal meaning and societal value.

\section{Material explorations on the body}

The second work we discuss here, Sound Embracers, is a kind of instrument that links body movement to sound generation (Figs. 7, 8 and 9). This 'garment-instrument' consists of a knitted collar (similar to a large scarf) with integrated knitted stretch sensors

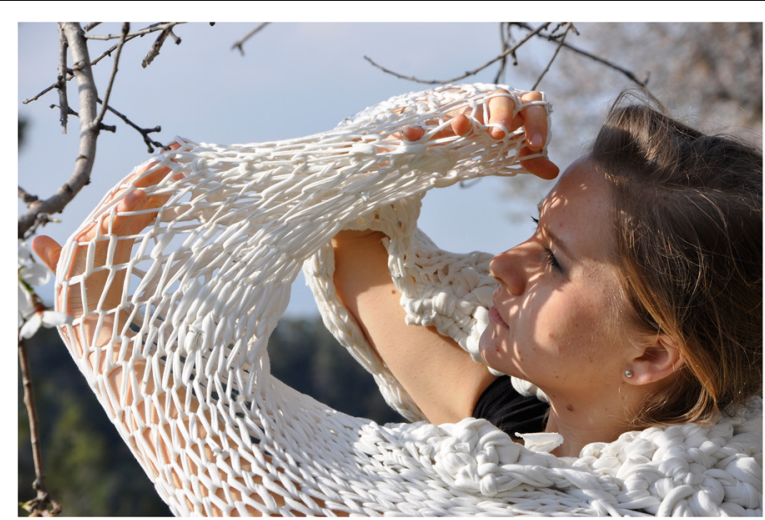

Fig. 7 Sound Embracers (v.1) is made of a knitted cotton net. It relates to the body by supporting detailed touch. Its context of use is exploring the environment 


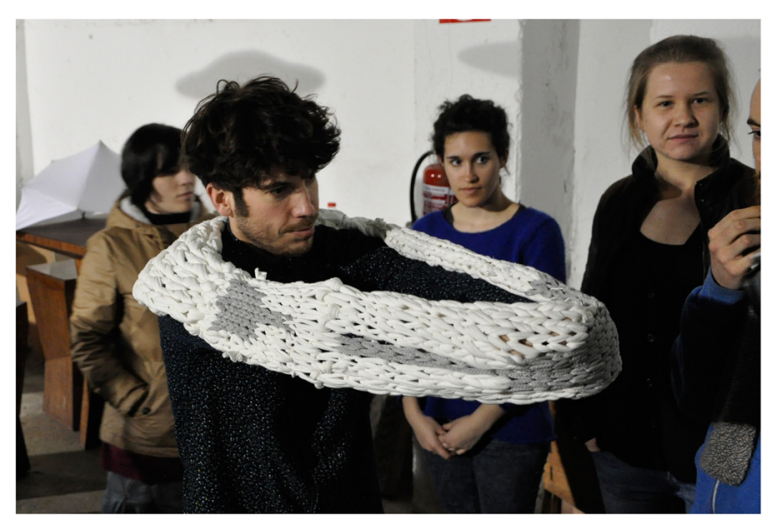

Fig. 8 Sound Embracers (v.2) is made of a knitted net, stretch sensors, and speakers. It relates to the body by constraining the arms. Its context of use is music performance

and small speakers. When used in live performance, the collar can be connected to an amplifier or external speakers (like a guitar) to better enable amplification. The starting point for the design of Sound Embracers was to empower an explorative behaviour by triggering curiosity. While sitting down, constraining arm movements with a knitted net helped focusing the attention of the designer on his/her fingers. This first person experiment with felt-experience allowed for a detailed exploration of the environment using the fingertips (see Fig. 7). The wearer's sense of touch was enhanced by foregrounding texture, temperature and humidity rather than sight.

In the second iteration (Fig. 8), the experience of the net embracing the body became so distracting that any notion of context disappeared completely. The focus moved from playing with the fingers, to exploring the space that formed between the arms. Stretch sensors were added to the knitted net to sense deformation of the collar and transform it into sound. The intention was to create an object that would allow for the combination of dance and music performance. In the third iteration (Fig. 9), the dialogue between the net and the arms was developed further, allowing the performer to twist and turn the net. However, due to the difficulties of creating a functioning music instrument (latency, accuracy and robustness issues) the knitted collar moved to the

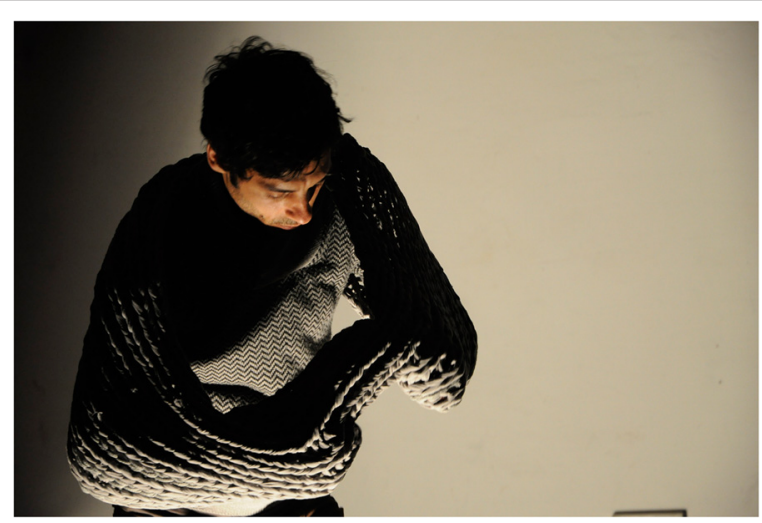

Fig. 9 Sound Embracers (v.3) is made of a knitted net, stretch sensors and connects to a sound system. It relates to the body by affording twisting and turning the arms. Its context of use is being a support instrument in a performance 
background. The role of the wearable shifted. It became a support instrument to create soundscapes and allow other instruments to take a leading role in terms of music making. This shift gave bodily expression a central role in the music performance.

The design process behind Sound Embracers revolved around the relation between the material properties and the body performance. The stretch qualities of the yarns, the structure (openness) of the knit and the weight of the 'instrument' were in constant dialogue with the body in terms of positioning, comfort, and expressiveness. As the piece evolved, Sound Embracers moved from a light open knitted structure that enabled the fingers to move and open up the knit; to a closed, stretchy structure that supports twisting and stretching the knit without loosening it in order to create sounds.

Framing the design process by means of material explorations on the body brings awareness to the personal intricacies that are necessary to move from designing an object to be used, to an object to be worn. The body necessarily becomes part of the emerging design, and in the case of Sound Embracers, part of the 'instrument's' look, structure, and functionality. The continuous dialogue between the body and the object allowed a continuous reshaping of the material properties embedded in textile structure, and the body movement that these capabilities elicit. The result is a performance where no single entity has meaning without the other. They cannot be treated as independent.

Mastering interaction between the body and material risks reducing the importance of where interactions take place. Interaction with design may be meaningful for the wearer, but without context, the design cannot be situated. It is not a coincidence that Sound Embracers ended up as a music instrument. Music performance closely relates the player with the instrument. It creates an intimate bond between them. Mastering this relation becomes a quest, detached from when and where it is practiced. The distracting power of the body is a red flag when designing wearables. Movements such as Quantified Self [35] and research into Somaesthetics [21] offer a glimpse of the kinds of self-reflexive and self-absorbed experience that are possible when the body becomes the primary context for design.

\section{Material explorations on the body in context}

The initial goal of Trailblazer (Figs. 10, 11 and 12) was to support balance when running up and down a mountain. The garment was constructed of a single piece of insulation felt made of natural wool, laser cut using an industrial machine. It functioned by connecting the wearer's arms together across the upper part of the back (Fig. 10) in a similar way to the upper part of a jacket. The intention was to create a sturdy but playful shape that would fit the body and the action of running. In the second iteration the context of Trailblazer evolved to a generalise notion of running: in the city, the mountains, along a beach... For this version, the designers introduced vibration sensors to not only support, but also guide the balance of the body and the movement of the arms (Fig. 11). The placement of sensors was carefully undertaken by analysing the movement of the body while running. For this iteration, synthetic felt was used instead of natural felt because it emitted less odours when laser-cut and the finish was better as synthetic felt doesn't burn during laser cutting, whereas natural felt does. In the final iteration (Fig. 12) it was discovered that cues to guide balance may be experienced as cues to guide direction-taking, similar to when a 


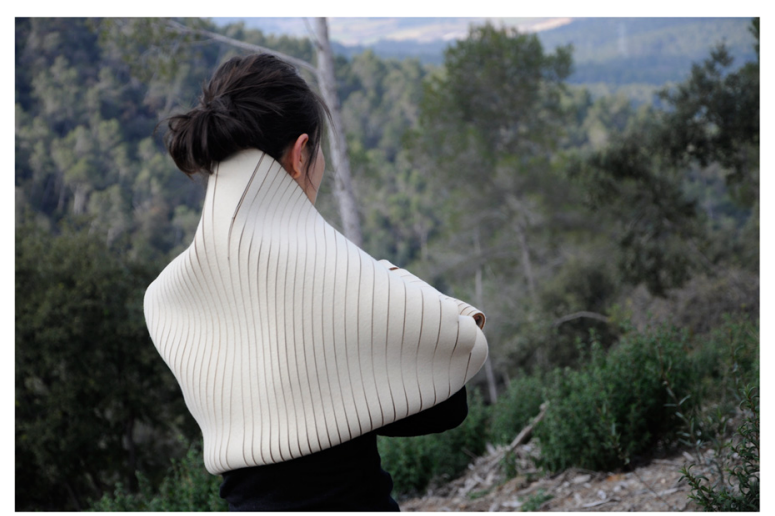

Fig. 10 Trailblazer (v.1) is made of natural felt for insulation. It relates to the body by supporting balance. Its context of use is running in the mountains

cyclist leans into the handlebar of their bicycle when they turn. This discovery prompted the designers to evolve the context into navigating unfamiliar locations without the need for a map. This new use transformed the design into a service where Trailblazer was one part of a larger system. A shop and a web based interface for selecting running routes were also developed in connection to the garment.

For some designers, framing the design process through: Material explorations on the body in context may be experienced as constraining and difficult, particularly when the designer lacks knowledge of the context they are designing for. In the case of Trailblazer, most members of the design team were avid runners. Their personal experience allowed them to "remember" or "replay" the experience of running rather than imagining or discovering it for the first time. Yet even with contextual knowledge, there are many things to consider when designing for specific contexts (e.g., size of the body, comfort, friction, other garments used in complement, the weather, the chosen terrain, performance and strength of body, as well as materials, possible distractions, length of the run, etc.), and the view of the novice can bring much insight [36]. Requirements that arise from 'being there' may seem overwhelming at first. Especially when the direction of a project is not defined. However, once initial frictions are resolved and the designers are able to accept not knowing where they are heading, experiencing material

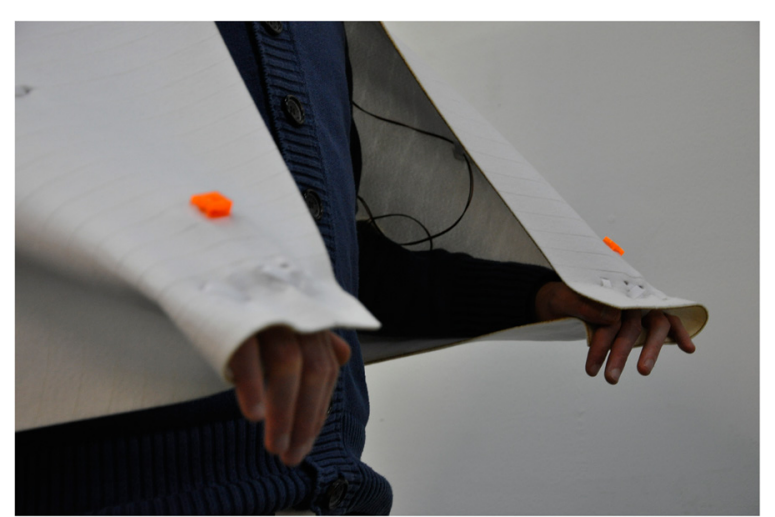

Fig. 11 Trailblazer (v.2) is made of synthetic textile for thermal insulation, and vibration motors. It relates to the body by supporting and guiding balance. Its context of use is running in general 


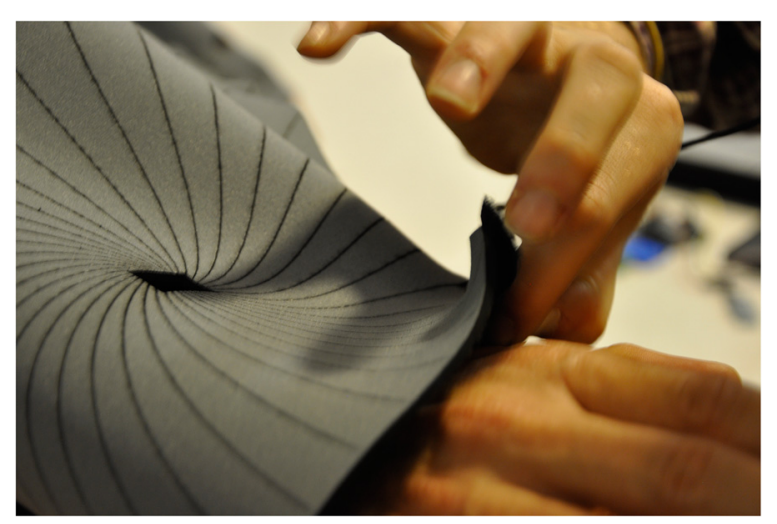

Fig. 12 Trailblazer (v.3) is made of technical textiles, and vibration motors. It relates to the body by guiding direction. Its context of use is running \& sightseeing

on a moving body in context creates a source of inspiration that is situated, embodied and relational. The decision making process becomes tacit, one just "feels" if the material, shape, or even the direction the project is going is the right one.

When a person is situated in context, they sense the environment through their body, interact with garments through their body and fulfil goals using their clothed, accessorised and thus augmented body in an intuitive manner. A designer's augmented body filters data, picking up what is relevant to the designer's goals, including what might impede these goals. By using their own bodies in context in this way, designers are able to achieve the necessary intimacy and personal meaning-making required in worn objects. Being in context also maintains focus on social value. A critique to this hyper-localised approach might wonder if the resulting garment could be used in a context other than the one it was designed for. Exploration of such questions can enable a designer to focus their design decisions to arrive at appropriate outcomes.

\section{Discussion}

\section{Situated, embodied, \& connected: reflections on findings}

Our aim in this article is to bring awareness to the personal intricacies that are necessary to move from designing an object to be used, to an object to be worn. We advocate an embodied, situated and connected approach to the design and use of wearables. As Gallagher explains, embodied ideation, communication and collaboration techniques enable enhanced creative engagement and assist creativity [37]. His findings align well with Shusterman's assertion that interaction outcomes are experientially richer when embodied communication and discovery is integral to development [21]. While Christian Gärtner [38] discusses that there are clear limitations in the literature around social embodiment, if we follow his view that the body is the ultimate locus of knowing, then situating the body in a social setting can provide extended opportunities for enriched interactions.

In the previous section we analyzed three cases: Open Up (framed by the material), Sound Embracers (framed by the material on the body), and Trailblazer (framed by the material on the body in context), to demonstrate how a dialogue between theory and practice can advance thinking, as well as inform practice. In this section we would like to reflect on our findings as an early attempt to formalize an embodied, situated \& 
connected approach to the design of soft wearables. The three cases presented here each have their advantages and disadvantages. Comparing them better places us to understand the implications of foregrounding different concerns when designing soft wearables, in particular when we take into account the emerging opportunities and challenges brought to light by each case.

\section{Opportunities}

Exploring materials on, with and through the body in context can allow meaning to emerge directly from interaction with the material if one remains open to the unexpected, looking to perceived "missteps" as inspiration. This approach can allow designers to design for the senses from the senses, opening the door for multisensory interactive qualities and complex interrelations between the senses. In the presented cases, in the shift from iteration 1 to 2, Open Up (which neither used the body nor context to frame the design process) lost its relation to the body entirely, shifting the focus from feeling the air around the wearer to reliance on a sensor that measured proximity to others to activate the nets. Sound Embracers (which used the body's engagement with materials, not the context, to frame the design process) switched the focus from the touch of the fingers, to the space the knitted collar created between the arms and the body as it is stretched. Whereas, Trailblazer (which used the body in context to frame the design process) enhanced the wearer's relationship with their running body by shifting the focus from maintaining balance to guiding. This development stemmed from an exploration of the materials on, with and through the body in a clear context. The results were experienced as meaningful in ways that the other two cases were not.

We believe it is crucial to understand that ideating on the body can allow a designer to combine language with movement in abstract ways, and to think through and with the full range of their movement capabilities and perceptions. Such explorations can assist the designer to postpone the moment of defining outcomes, thereby extending the process of not knowing to enable unexpected results to emerge. It can also allow the designer to become personally experienced in the context with which their design is concerned, and to relate functionality through both material and use by means of the body. To demonstrate: Open Up was concerned with the concept of symbiotic relations detached from specific actions. In contrast, Trailblazer was about running and Sound Embracers was about exploring the surroundings-both specific actions that required intense involvement of the body. With each iteration, Trailblazer and Sound Embracers arrived at increased understanding of how to support these actions, each time becoming more specific.

Prototyping on the body can afford the emergence of functionality, giving value to subtle experiences, small details, and elements that may otherwise be overlooked. It can help a designer to identify which details to focus on, through access to direct and instant feedback. It can allow for quick changes and iterations in an intuitive way, and can help develop: a relational understanding of the chain of events, sensitivity to the implications of changes, and an awareness of the subtle relations that any design experienced by the body may engender. While Open Up stayed quite conceptual throughout and had to be wizard of oz'ed at the end, Sound Embracers was performed live at the end of the project. It was used to provide a supportive sonic atmosphere for a didgeridoo player during a concert. The prototyping of Sound Embracers focused on technology development, rather than end usage. Once usage was determined, a musician had to select the scale and selection of tones to map to the stretchiness of the kitted collar/ 
scarf. In the case of Trailblazer, its motive "Just run" was developed at the end of the project as communication material. Significantly, the team was able to maintain a strong focus and direction over the three iterations without defining functionality from the beginning. They also created a service that was in line with the experience the prototype could provide to users. All was achieved by keeping the process embodied and situated.

\section{Challenges}

Restricting the focus to explorations between the body and material during design and use reduced the importance of where interactions take place. In such cases (when becoming self-absorbed), interaction with the body may be meaningful for the designer/ user, but without context, the action cannot be situated. The typical reasoning in these cases is the following: it doesn't matter where the action takes place, it can be used everywhere as the focus is on the body. Sound Embracers, for example, became a tool, a musical instrument to support any kind of instrument for any kind of song. Without realizing, the sounds and movements the designers were using for testing the prototype become the context for development and use. Once a performer and place of presentation were found for the piece the designers had to completely redo the mapping so that it made sense in the new context.

Ideation in context can be experienced as too constraining and can create a creativity blockage. Ideation in context requires the designer to think inside the box rather than outside the box. Doing so can, at times, feel like a dead end, and designers can become frustrated on a personal level. Such moments require finding ways to disrupt the design experience. The easiest solution, if the designer wants to keep an embodied approach, is to change places or imagine other contexts (and lose the situatedness). Both Open Up and Sound Embracers changed contexts after the first iteration. Living surrounded by nature, feeling the space around and being in touch with the earth (soil, plants, animals, ...) transformed into living in a city, being at a party, or performing in a concert.

Neither electronic nor mechanical structures fit well with the body. They are not typically designed to be used on moving, unprotected and unstable "surfaces" that include elements such as skin and muscle structures that move. While this is changing, with the advent of new, flexible materials, mechanical and electric engineers typically undertake explorations and tests on a bench in a lab, because electronic components and the elements of mechanical structures tend to be well suited to being fixed to hard surfaces and worked on in a stable environment. Prototyping and testing electronics directly on the body thus can be difficult. Doing so in context brings further challenges. In the case of Open Up, for example, the programing and material explorations were done on a table in a lab. The "body" used (the table), was static and horizontal and the context (the lab), an enclosed area with people walking around. If the designers wanted to use another body or context, they would have to imagine them from the ground up. However, without leaving the lab, they would not be able to decontextualize themselves from the lab. The lab, therefore will have an impact on the creative process.

\section{Conclusion}

The cases we analyse here provide insight into the roles of the body, materiality and context for the design of soft wearables. They demonstrate that, while all elements are key, context is essential for meaning-making, as it takes the wearer's focus away from a 
self-absorbed (or materially absorbed) perspective into a social space. To realise such outcomes the designer of soft wearables needs to move away from their drawing board and immerse themselves-designing, prototyping and testing-in the contexts they envision for use. Doing so affords direct engagement with the constraints that come from context, the performing body, material properties and functionality, and enables designers to frame 'meaningful' design opportunities. The requirements that arise from 'being there' may seem overwhelming at first. However, once initial frictions are resolved and the designers are able to accept not knowing where they are heading, experiencing material on a moving body in context creates a source of inspiration that is situated, embodied and relational.

To make the shift from studio to context, from rigid to soft, and from held or carried to worn, we use HGI (Human Garment Interaction) as a counterpoint to HCI. Engaging directly with materials, body and context to meet and recognise the challenges that come up as opportunities, and develop rich, unexpected responses. To assist other designers to follow this lead, we provide three broad recommendations:

1. Exploring materials on, with and through the body in context can allow meaning to emerge directly from interaction with the material if one remains open to the unexpected. This approach can allow designers to design for the senses from the senses, opening the door for multisensory interactive qualities and complex interrelations between the senses.

2. Ideating on the body can allow a designer to combine language with movement in abstract ways, and to think through and with the full range of their movement capabilities and perceptions. Such explorations can assist the designer to postpone the moment of defining outcomes, thereby extending the process of not knowing to enable unexpected results to emerge.

3. Prototyping on the body can afford the emergence of functionality, giving value to subtle experiences, small details, and elements that may otherwise be overlooked.

Moving forward, the question we pose now is whether collocating interactions between soft wearables may further enhance their potential to bring meaning to individual, as well as social experiences. Will doing so further enrich the embodied, situated and connected experiences their wearers engage in?

Following Linde [39], mobile and networked technologies are no longer "neutral layers in urban living, but are rather an integrated part of the materialities of architecture and urban planning, in the social dimensions of city life, and in emerging cultural frameworks". Wearables and mobile technologies may not be integrated materially into architecture, but they are often momentarily integrated-physically, spatially, and socially. The potential for them to have meaningful (even if ephemeral) impact in social spaces enables what Castells [40] describes as a "space of flows": a materialisation of social interaction, performed with and through the combination of technological and material possibility and the networked communication that social, mobile and networked architectures afford (as cited in [39]). This potential opens up the question of how meaning can emerge in the interplay between people, soft wearables and place, in ways that go beyond a consideration of a specific context. Doing so might "allow us to reengineer an infinite number of small scale relationships" [41]. At the same time: Might the liminal spaces of sociality-the "complex entanglement taking place between citizens, 
public spaces, and things" [42]-be designed to support the inherent, emerging and performative potential of wearables that are soft, embodied, situated and connected? Our intention now is to engage with these questions.

\title{
Endnotes
}

\author{
${ }^{1}$ Escola Superior de Disseny, Barcelona, S. \\ ${ }^{2}$ Institute for Advanced Architecture Catalonia, Barcelona, S. \\ ${ }^{3}$ Technical University, Eindhoven, NL.
}

\section{Acknowledgements}

We would like to thank Xavi González and Carlos Gomez from IAAC, Marina Castán from ESDI, and Eunjeon Jeon, Sietske Klooster, Eva Deckers, Martijn ten Bhömer, Kristi Kuusk, and Marina Toeters for supporting this research studio. Our appreciation as well goes to the students both from IAAC and ESDi for their enthusiasm and perseverance, and finally to all IAAC and ESDi staff for supporting this project.

\section{Authors' contribution}

All authors read and approved the final manuscript.

\section{Competing interests}

The authors declare that they have no competing interests.

\section{Author details}

'Eindhoven University of Technology, P.O. Box 513, Eindhoven 5600 MB, The Netherlands. ${ }^{2}$ University of Southern Denmark, Universitetsparken 1, 6000 Kolding, Denmark.

Received: 27 January 2016 Accepted: 31 May 2016

Published online: 17 June 2016

\section{References}

1. Ryan SE (2014) Garments of paradise: wearable discourse in the digital age. MIT Press, Cambridge

2. Bryson D (2009) Designing smart clothes for the body. In: McCann J, Bryson D (eds) Smart clothes and wearable technology. Woodhead, UK

3. Kapp E (1877) Philosophie der Teknik: Zur Entstehungsgeschichte der Kultur aus neuen Gesichtspunkten [Fundamentals of a Philosophy of Technology: The Genesis of Culture from a new Perspective] Westermann., pp 44-45, cited and translated by Mitcham in Thinking Through Technology, 24

4. Mitcham C (1994) Thinking through technology: the path between engineering and philosophy. University of Chicago Press, Chicago

5. Mumford L (1967/1970) The myth of the machine, 2 vols. Harcourt Brace Jovanovich, New York

6. Ortega GJ (1939) Ensimismamiento y alteración. Meditación de la técnica (Self-absorption and alteration. Meditation on Technique). Espasa Calpe, Buenos Aires

7. Heidegger M (1977) (Tr: Lovitt W) the question concerning technology and other essays. Harper Torchbooks, New York

8. Omico O, van Zijverden M, Fejér T, Chen Y, Lubbers E, Heuvelings M, Aïssaoui S, Schepperheyn V (2013) Crafting wearables: interaction design meets fashion design. In: Proceedings of CHI EA '13. ACM, New York, pp 2875-2876

9. Wilde D (2011) Swing that thing: moving to move, PhD Diss. Monash University, Melbourne

10. Tomico O, Winthagen VO, van Heist MMG (2012) Designing for, with or within: 1st, 2nd and 3rd person points of view on designing for systems. In: Proceedings of the 7th Nordic Conference on Human-Computer Interaction. ACM, New York, pp 180-188

11. Sheets-Johnson M (1988) The primacy of movement. John Benjamins, Amsterdam

12. Clark A (2010) Supersizing the mind. Oxford University Press, New York

13. Wilde D, Schiphorst T, Klooster S (2011) Move to design. Design to move. Interactions 18(4):22-27

14. Schön DA (1992) The theory of inquiry: Dewey's legacy to education. Curric Inq 22(2):119-139

15. McCarthy J, Wright P (2007) Technology as experience. MIT Press, Cambridge

16. Salter C (2010) Entangled, Technology and the transformation of performance. MIT Press, Cambridge

17. Wilde DA (2009) New Performativity: wearables and body devices, Proc. Re:live Media Art History., pp 184-190

18. Debord G, \& Wolman GJ (1956) A user's guide to détournement. Retrieved 27 May, 2015 from http://www.bopsecrets.org/SI/detourn.htm.

19. Gaver W (2001) Presence project. RCA: CRD Research Publications, London

20. Bourriaud N (2002) Relational aesthetics. La presses du reel, Paris

21. Shusterman R (2008) Body consciousness: a philosophy of mindfulness and somaesthetics. Cambridge University Press, Cambridge

22. Sundström P, Vaara E, Solsona J, Wirström N, Lundén M, Laaksolhati J, Waern A, Höök K (2011) Experiential artifacts as a design method for somaesthetic service development. In: Proceedings of the 2011 ACM symposium on The role of design in UbiComp research \& practice. The 2011 ACM Conference on Ubiquitous Computing. ACM, NY, pp 33-36

23. Hansen LK, Kozel S (2007) Embodied imagination: a hybrid method of designing for intimacy. Digital Creativity 18(4):207-220

24. Kozel S (2008) Closer: performance, technologies, phenomenology. MIT Press, Cambridge 
25. Schiphorst T, Andersen K (2004) Between bodies: Using experience modeling to create gestural protocols for physiological data transfer. In: Proceedings of the conference on human factors in computing systems (CHI'O4) fringe papers. ACM, New York

26. Corness G, Schiphorst T (2013) Performing with a system's intention: embodied cues in performer-system interaction. In: Proceedings of the creativity \& cognition conference. ACM, New York, pp 156-164

27. Stjernholm J (2011) Moving through the virtual: a dramaturgy of choreographic practice and perception. Dance dramaturgy: catalyst, perspective and memory. In: Proceedings of the society of dance history scholars conference. Toronto University: SDSH, Toronto

28. Kirsh D (2010) Thinking with the body. In: Proceedings of the 32nd annual conference of the cognitive science society. Cognitive Science Society, Austin, pp 2864-2869

29. Ross $P$, Wensveen $S$ (2010) Designing aesthetics of behavior in interaction: Using aesthetic experience as a mechanism for design. Int J Des 4(2):3-13

30. Hummels C, Overbeeke CJ, Klooster S (2007) Move to get moved: a search for methods, tools and knowledge to design for expressive and rich movement-based interaction. Pers Ubiquit Comput 11(8):677-690

31. Djajadiningrat T, Matthews B, Stienstra M (2007) Easy doesn't do it: skill and expression in tangible aesthetics. Pers Ubiquit Comput 11(8):657-676

32. Loke L, Robertson T (2013) Moving and making strange. ToCHI 20(1):7

33. Uğur S (2013) Wearing embodied emotions, a practice based design research on wearable technology. Springer, Milan

34. Jeon E (2011) 'Enriched aesthetic Interaction' through sense from haptic visuality. In: Proceedings of the International Design Alliance (IDA) Congress Education Conference. IDA, Taipei, pp 28-35

35. Lupton D (2016) The quantified self. Polity, Cambridge

36. Mitchell WJ (2005) Placing words: symbols, space and the city. MIT Press, Cambridge

37. Gallagher S (2005) How the body shapes the mind. Clarendon, Oxford

38. Gärtner C (2013) Cognition, knowing and learning in the flesh: Six views on embodied knowing in organization studies. Scand J Manag 29(4):338-352

39. Linde P (2014) Emerging publics: totem-poling the 'We's and 'Me's of citizen participation. In: Ehn P. Nilsson EM, Topgaard R (eds) Making Futures: Marginal notes on innovation, design and democracy. MIT Press, Cambridge

40. Castells M, Fernández-Ardèvol M, Linchuan Qiu J, Araba S (2007) Mobile communications and society: a global perspective. MIT Press, Cambridge

41. Paolos E (2008) Citizen science: enabling participatory urbanism. In: Handbook of research on urban informatics. \|Gl Global, Hershey

42. Telier A, Linde P, Ehn P, Binder T, de Michaelis G, Jacucci G, Wagner I (2011) Design things. MIT Press, Cambridge

Submit your manuscript to a SpringerOpen ${ }^{\oplus}$ journal and benefit from:

- Convenient online submission

Rigorous peer review

- Immediate publication on acceptance

- Open access: articles freely available online

- High visibility within the field

Retaining the copyright to your article

Submit your next manuscript at $\gg$ springeropen.com 